\section{(2) OPEN ACCESS}

\title{
Workload and cross-harvest kidney injury in a Nicaraguan sugarcane worker cohort
}

\author{
Erik Hansson (1) , 1,2 Jason Glaser, ${ }^{1,3}$ Ilana Weiss, ${ }^{1}$ Ulf Ekström, ${ }^{1,4}$ Jenny Apelqvist, ${ }^{1,4}$ \\ Christer Hogstedt, ${ }^{1,5}$ Sandra Peraza, ${ }^{1,6,7}$ Rebekah Lucas, ${ }^{1,8}$ Kristina Jakobsson, ${ }^{1,2,9}$ \\ Catharina Wesseling, ${ }^{1,5}$ David H Wegman ${ }^{1,10}$
}

\begin{abstract}
- Additional material is published online only. To view please visit the journal online (http://dx.doi.org/10.1136/ oemed-2019-105986).
\end{abstract}

For numbered affiliations see end of article.

Correspondence to Jason Glaser, La Isla Network, Washington, DC 1441 L St NW, USA; jason@laislanetwork.org

A previous version of parts of this work has been presented as a poster and conference abstract at the Third International Workshop on Chronic Kidney Diseases of Uncertain/Non-Traditional Etiology in Mesoamerica and Other Regions, March 2019 in San José, Costa Rica.

Received 27 May 2019 Revised 20 August 2019 Accepted 18 September 2019

\section{ABSTRACT}

Objectives To examine the association between workload and kidney injury in a fieldworker cohort with different levels of physically demanding work over a sugarcane harvest, and to assess whether the existing heat prevention efforts at a leading occupational safety and health programme are sufficient to mitigate kidney injury.

Methods Biological and questionnaire data were collected before $(n=545)$ and at the end $(n=427)$ of harvest among field support staff (low workload), drip irrigation workers (moderate), seed cutters (high) and burned sugarcane cutters (very high). Dropouts were contacted (87\%) and reported the reason for leaving work. Cross-harvest incident kidney injury (IKI) was defined as serum creatinine increase $\geq 0.30 \mathrm{mg} / \mathrm{dL}$ or $\geq 1.5$ times the baseline value, or among dropouts reporting kidney injury leading to leaving work.

Results Mean cross-harvest estimated glomerular filtration rate change was significantly associated with workload, increasing from $0 \mathrm{~mL} / \mathrm{min} / 1.73 \mathrm{~m}^{2}$ in the lowmoderate category to $-5 \mathrm{~mL} / \mathrm{min} / 1.73 \mathrm{~m}^{2}$ in the high and $-9 \mathrm{~mL} / \mathrm{min} / 1.73 \mathrm{~m}^{2}$ in the very high workload group. A similar pattern occurred with IKI, where low-moderate workload had $2 \%$ compared with $27 \%$ in the very high workload category. A healthy worker selection effect was detected, with $32 \%$ of dropouts reporting kidney injury. Fever and $C$ reactive protein elevation were associated with kidney injury.

Conclusions Workers considered to have the highest workload had more cross-harvest kidney damage than workers with less workload. Work practices preventing heat stress should be strengthened and their role in preventing kidney damage examined further. Future occupational studies on chronic kidney disease of unknown aetiology should account for a healthy worker effect by pursuing those lost to follow-up.

\section{INTRODUCTION}

Check for updates

(C) Author(s) (or their employer(s)) 2019. Re-use permitted under CC BY-NC. No commercial re-use. See rights and permissions. Published by BMJ.

To cite: Hansson $\mathrm{E}$, Glaser J, Weiss I, et al. Occup Environ Med 2019;76:818-826.
Chronic kidney disease in the absence of diabetes, hypertension or other known risk factors, thus of unknown aetiology $(\mathrm{CKDu}),{ }^{1}$ is estimated to have caused tens of thousands of deaths in Mesoamerica. ${ }^{2}$

Hypotheses of the aetiology of CKDu include repeated heat stress and dehydration, pesticides, drinking water contaminants, infectious diseases, and non-steroidal anti-inflammatory drugs. ${ }^{3}$ Studies have presented increased prevalence of reduced kidney function ${ }^{45}$ and increased kidney injury incidence across work shifts ${ }^{6-11}$ and across harvests ${ }^{10-14}$

\section{Key messages}

What is already known about this subject?

- In Mesoamerica, a region affected by chronic kidney disease of unknown aetiology, sugarcane workers are at a high risk of kidney injury during harvest.

What are the new findings?

- There was evidence of more kidney injury with physically more demanding sugarcane harvest jobs.

- A healthy worker selection effect was revealed when dropouts were interviewed, with results showing a higher incidence of cross-harvest kidney injury in this group.

- Elevated C reactive protein and self-reported fever were more common in those with kidney injury.

How might this impact on policy or clinical practice in the foreseeable future?

- This study describes the baseline of the 3-year Adelante Initiative intervention study, indicating the need for further improvements of working conditions for manual workers with heavy physical workload in a hot climate.

among sugarcane workers, a group performing strenuous manual work in high temperatures, ${ }^{15}$ indicating that heat stress and dehydration likely contribute to initiation or progression of CKDu.

There is some evidence to suggest reducing heat stress and dehydration may reduce cross-harvest kidney injury. ${ }^{1016}$ The sugarcane mill Ingenio San Antonio (ISA) in Chinandega, Nicaragua, has gradually enhanced efforts to improve occupational health among fieldworkers ${ }^{17-19}$ and has added water intake, rest and shade to injury prevention efforts via the following principles:

- Harvest employment starts with a 2-week acclimatisation period.

- Fieldworker groups considered at high risk of kidney injury have access to tents for rest in shade during mandated breaks. Movable tents made of a netted fabric are open on two sides, thus giving shade while also being ventilated.

- Cane and seed cutters have stools for seated, shaded rest. 
Table 1 Demographic composition, heat and physical effort exposure, intervention, and sampling strategy of studied job categories of fieldworkers

\begin{tabular}{|c|c|c|c|c|}
\hline & Burned cane cutters & Seed cutters & $\begin{array}{l}\text { Drip irrigation repair } \\
\text { workers }\end{array}$ & Field support \\
\hline$n^{*}$ & 158 & 190 & 128 & 54 \\
\hline \multicolumn{5}{|l|}{ Demographics } \\
\hline$\%$ men & 100 & 72 & 53 & 65 \\
\hline Age, median (IQR) & $30(25-37)$ & $26(23-33)$ & $29(23-34)$ & $31(25-35)$ \\
\hline \multicolumn{5}{|l|}{ Work characteristics } \\
\hline Previous harvests, median (IQR) & $7(4-13)$ & $4(2-6)$ & $4(2-6)$ & $5(1-8)$ \\
\hline First ever harvest, $\mathrm{n}(\%)$ & 0 & $14(7)$ & $10(8)$ & $6(11)$ \\
\hline Work setting & $\begin{array}{l}\text { Cane fields burned } 12 \text { hours } \\
\text { earlier }\end{array}$ & Green cane & Open fields & Open fields \\
\hline Work task & $\begin{array}{l}\text { Cut burned cane, top foliage } \\
\text { and leave in rows on ground. }\end{array}$ & $\begin{array}{l}\text { Cut cane at stem, then into } \\
3-4 \text { pieces. Later, pieces are } \\
\text { bundled into packages of } \\
10-11.5 \mathrm{~kg} \text {. }\end{array}$ & $\begin{array}{l}\text { Repair underground drip } \\
\text { irrigation tubes requiring } \\
\text { digging, bending, prolonged } \\
\text { squatting. }\end{array}$ & $\begin{array}{l}\text { Supervisors, work organisers, health } \\
\text { promoters, hydration operators. Some } \\
\text { occasionally walk long distances. }\end{array}$ \\
\hline Physical demands $t$ & Very high & High & Moderate & Light \\
\hline Work schedule & 06:00-noon & $\begin{array}{l}06: 00-14: 00 \text {, cutting ends at } \\
\text { noon }\end{array}$ & 06:00-14:00 & 06:00-noon-14:00 \\
\hline Mobile clinic & Daily & Daily or every other day & None & \multirow{6}{*}{$\begin{array}{l}\text { Many are implementers of the } \\
\text { intervention with access to water } \\
\text { and shade, but no clear rest } \\
\text { recommendations. }\end{array}$} \\
\hline Health promoter & Yes & Yes & Every other day & \\
\hline Water distribution & Yes & Yes & Yes & \\
\hline Lunch provided & Yes, end of work & Yes, during noon rest & No & \\
\hline Tent & Yes & Yes & Yes & \\
\hline Stool provided & Yes & Yes & No & \\
\hline \multicolumn{5}{|l|}{ Population sampling } \\
\hline Sampling strategy & All & All & $\begin{array}{l}\text { Two of four work groups (one } \\
\text { female, one male) }\end{array}$ & $\begin{array}{l}\text { All present in fields with job groups } \\
\text { studied }\end{array}$ \\
\hline Mid-harvest testing, n (\%) & $137(87)$ & $151(79)$ & $96(75)$ & $19(35)$ \\
\hline Dropout, $\mathrm{n} \ddagger(\%)$ & $33(21 \ddagger)$ & $46(23 \ddagger)$ & $23(17 \ddagger)$ & $12(21 \ddagger)$ \\
\hline $\begin{array}{l}\text { Baseline eGFR, median (IQR) (mL/ } \\
\left.\min / 1.73 \mathrm{~m}^{2}\right)\end{array}$ & $97(80-114)$ & $110(87-122)$ & $109(93-123)$ & $112(96-121)$ \\
\hline \multicolumn{5}{|l|}{ Questionnaire } \\
\hline Pesticide use during harvest§, n (\%) & $6(5)$ & $3(2)$ & $3(3)$ & $2(5)$ \\
\hline Incident fever§, n (\%) & $12(9)$ & $16(11)$ & $12(11)$ & $4(10)$ \\
\hline Chikungunya during harvest, $\mathrm{n}(\%)$ & $5(3)$ & $3(2)$ & 0 & $1(2)$ \\
\hline NSAID use, $\mathrm{n}(\%)$ & $40(25)$ & $39(21)$ & $29(23)$ & $8(15)$ \\
\hline Current smoking, $\mathrm{n}(\%)$ & $55(35)$ & $55(29)$ & $23(30)$ & $10(19)$ \\
\hline $\begin{array}{l}\text { Daily liquid intake end-harvest vs } \\
\text { baseline change§ (L), median (IQR) }\end{array}$ & $4.9(2.1-8.3)$ & $2.8(0.1-5.9)$ & $4.4(1.8-5.8)$ & $2.6(1.0-4.4)$ \\
\hline $\begin{array}{l}\text { End-harvest electrolyte solution } \\
\text { (boli) intake§ (L), median (IQR) }\end{array}$ & $0.75(0-1.05)$ & $0.6(0-0.9)$ & $0.9(0-1.2)$ & $0.9(0.6-2)$ \\
\hline $\begin{array}{l}\text { End-harvest daily sugary beverage } \\
\text { intake§ (L), median (IQR) }\end{array}$ & $0.5(0.2-1)$ & $0.5(0.2-0.9)$ & $0.5(0.2-0.9)$ & $0.5(0.4-0.8)$ \\
\hline Diabetes, n (\%) & 0 & $1(1)$ & $1(1)$ & $1(2)$ \\
\hline $\begin{array}{l}\text { Hypertension (self-reported and/or } \\
\text { measured }(>140 / 90 \mathrm{~mm} \mathrm{Hg})), \mathrm{n}(\%)\end{array}$ & $5(3)$ & $6(3)$ & $2(2)$ & $1(2)$ \\
\hline
\end{tabular}

*Number of workers including those followed up at the end of harvest and dropouts contacted after harvest.

tPhysical demands order based on observation.

‡Denominator includes all recruited and also those who had no follow-up at all.

$\S 0$ ly includes those finishing the harvest.

eGFR, estimated glomerular filtration rate; NSAID, non-steroidal anti-inflammatory drug.

- Hydration operators refill personal thermoses and distribute 0.3 L electrolyte solution (bolis) hourly.

- Mandated breaks and workday lengths are adapted to avoid the most strenuous work after noon (table 1).

- Workers are given sun-protective clothing, including hat, eye shield or sunglasses, long-sleeved wicking shirt, and personal thermos in addition to other personal protective equipment.

- Mobile health clinics provide support for cutters in the field throughout the harvest.
The ISA is cooperating with the sustainable sugarcane roundtable Bonsucro, ${ }^{20}$ the Nicaraguan Sugarcane Producers Association and the non-governmental organisation La Isla Network ${ }^{21}$ in the 3-year Adelante Initiative ${ }^{22}$ intervention study. The longterm objective is to assess the impact of improved workplace interventions on preventing heat stress and kidney dysfunction. This paper reports on the first year evaluating the already existing occupational safety and health programme, informing recommendations for improvements. The observations will 
form a baseline for evaluation of further interventions. Here, we examine risk factors for baseline cross-harvest kidney injury with a specific focus on job tasks. A long-term aim is to determine if a sustainable programme of heat stress management can diminish kidney injury, and if successful can be adapted for use throughout the sugarcane industry and other impacted industries.

All workers were apprised of the study objectives and procedures and any questions were answered before signing an informed consent before enrolment in the study. This was done by our trained staff.

\section{METHODS}

\section{Study participants and data collection}

During sugarcane harvest (November-April), seasonal workers from Nicaragua, predominantly from areas close to the ISA, were employed directly by the mill after a routine pre-employment health screening (October-November 2017). Men with serum creatinine $(\mathrm{SCr}) \geq 1.3 \mathrm{mg} / \mathrm{dL}$ and women with $\mathrm{SCr} \geq 1.0$ $\mathrm{mg} / \mathrm{dL}$ applying for fieldwork jobs could be hired after re-evaluation 10-15 days later if retested values fell below those thresholds. At mid-harvest (February 2018) SCr was measured at the ISA laboratory in fieldworkers, as part of the ISA routine. Those with SCr elevation were placed on sick leave and dismissed if SCr remeasurement did not return to below cut-offs within a few weeks. Workers presenting with elevated creatinine could also be given leave, and a case series suggests this is common. ${ }^{23}$

Among the several manual field jobs, four were selected to represent a range of physical work: manual cutters of burned cane (very high physical demands), cutters of green cane for seeding (high physical demands), drip irrigation repair workers (medium physical demands) and field support staff (foremen and auxiliary logistics staff, health promoters, hydration operators; low physical demands) (table 1). Ranking of the physical demands of occupational groups was based on repeated qualitative observations by occupational hygienists and senior occupational physicians, taking into account postures, movements, handling of tools and weight carrying. We included all hired burned cane and seed cutters, together with half of the irrigation repair workers (one each of the two male and two female work teams), irrespective of baseline creatinine (table 1). All field support staff accompanying these fieldworkers were also included. A convenience sample of ISA administrative workers unexposed to fieldwork $(n=68)$ were recruited to provide an estimate of normal values in the region for an unexposed population. Those starting work were considered cohort participants, excluding one worker who worked only 4 days.

We organised the study baseline examination to accompany the ISA pre-employment screening: a brief questionnaire administered by our trained interviewers and an aliquot of morning blood and urine samples for analyses at Lund University. Workers were retested at end-harvest by prework shift serum and urine sampling and an extended questionnaire.

The questionnaire covered demographics, medical history, fever during the last week, symptoms within the past 2 weeks and liquid intake 24 hours prior to the interview at baseline and at the end of harvest. Height, weight, blood pressure and heart rate (HR) were measured at baseline and at end-harvest (height just baseline). At end-harvest, questions on personal habits, occupational history, infectious disease occurrence and pesticide exposure during harvest were added to the questionnaire.

Wet-bulb globe temperature (WBGT) was measured by trained ISA mobile health clinic personnel accompanying the workforce using QUESTemp34 (3M). Measurements were done hourly from 06:00 until shift end, with sample days distributed across the harvest.

Serum was separated from the cells at the ISA laboratory, frozen at $-77^{\circ} \mathrm{C}$ and transported to Sweden after each data collection period. Analyses were performed at Skåne University Hospital in Lund, Sweden, on a Cobas 701 instrument (Roche Diagnostics, Basel, Switzerland). Each individual's baseline and end-harvest samples were analysed during the same session. Sodium concentrations indicated that part of the serum samples had been inadequately mixed after thawing. Thus, all analytes were corrected using sample-specific correction factors, based on the ratio of measured sodium/true sodium level (assumed to be $140 \mathrm{mmol} / \mathrm{L}$; online supplementary 1 ).

Workers absent at end-harvest testing were visited at home, asked why they left work and administered a shortened end-harvest questionnaire. No blood or urine samples were taken.

\section{Outcome}

Two outcomes were examined. The first was a dichotomous measure for cross-harvest kidney injury, an event we named incident kidney injury (IKI), and the second was continuous cross-harvest estimated glomerular filtration rate (eGFR) change $(\Delta \mathrm{eGFR})$ calculated using the Chronic Kidney Disease Epidemiology Collaboration (CKD-EPI) formula. IKI was subdivided into IKI-Measured: SCr elevation at the end-harvest $\geq 0.30 \mathrm{mg} / \mathrm{dL}$ higher than or $\geq 1.5$ times the baseline value; or IKI-All: combining IKI-Measured with self-report by dropouts who left work or had been on sick leave due to SCr elevation. This subdivision enabled inclusion of dropouts in the analysis to account for healthy worker selection effect. IKI is an epidemiological measure distinct from the clinical criteria for acute kidney injury (AKI). The SCr elevation cut-offs were equal to the Kidney Disease Improving Global Outcomes (KDIGO) clinical criteria for AKI, which refer to shorter-term SCr changes rather than cross-harvest changes. ${ }^{24}$ Definitions of sugarcane worker cross-harvest kidney injury similar to IKI have been reported. $^{111314}$

\section{Statistical analysis}

Categories of potential risk factors were created. Job, the main exposure, is described in table 1. Age was divided into four 10 -year categories. Change in reported daily liquid intake at end-harvest versus baseline was categorised as reduced, increased by $0-5 \mathrm{~L}, 5-10 \mathrm{~L}$ and $>10 \mathrm{~L}$. Daily boli intake was categorised to $0,1-3$ and $>3300 \mathrm{~mL}$ bags, and sugary drinks (sweetened diluted fresh fruit drinks and soft drinks) intake to $<0.5 \mathrm{~L}$, 0.5-1.5 L and >1.5 L. Recent incident fever was defined as fever within the past week reported by participants who did not report fever at baseline. Baseline eGFR was categorised to >90, 75-89, $60-74$ and $<60 \mathrm{~mL} / \mathrm{min} / 1.73 \mathrm{~m}^{2}$.

Proportions with IKI-Measured and IKI-All by risk factor category were calculated and incidence ratios (IR) with 95\% CI estimated using univariate Poisson regression. Multivariate Poisson regression was performed by entering potential risk factors separately into a model with job as main exposure variable and age (continuous) and sex as covariates. Other factors were not adjusted for in the model as they may be on the causal pathway between job and outcome, but we tried a model with adjustment for baseline eGFR. To reduce the number of parameters, irrigation repair workers and field support staff were merged because there was no risk difference between them (table 2). Multivariate analyses were performed only for IKI-All due to insufficient number of workers with IKI-Measured. The IR for 


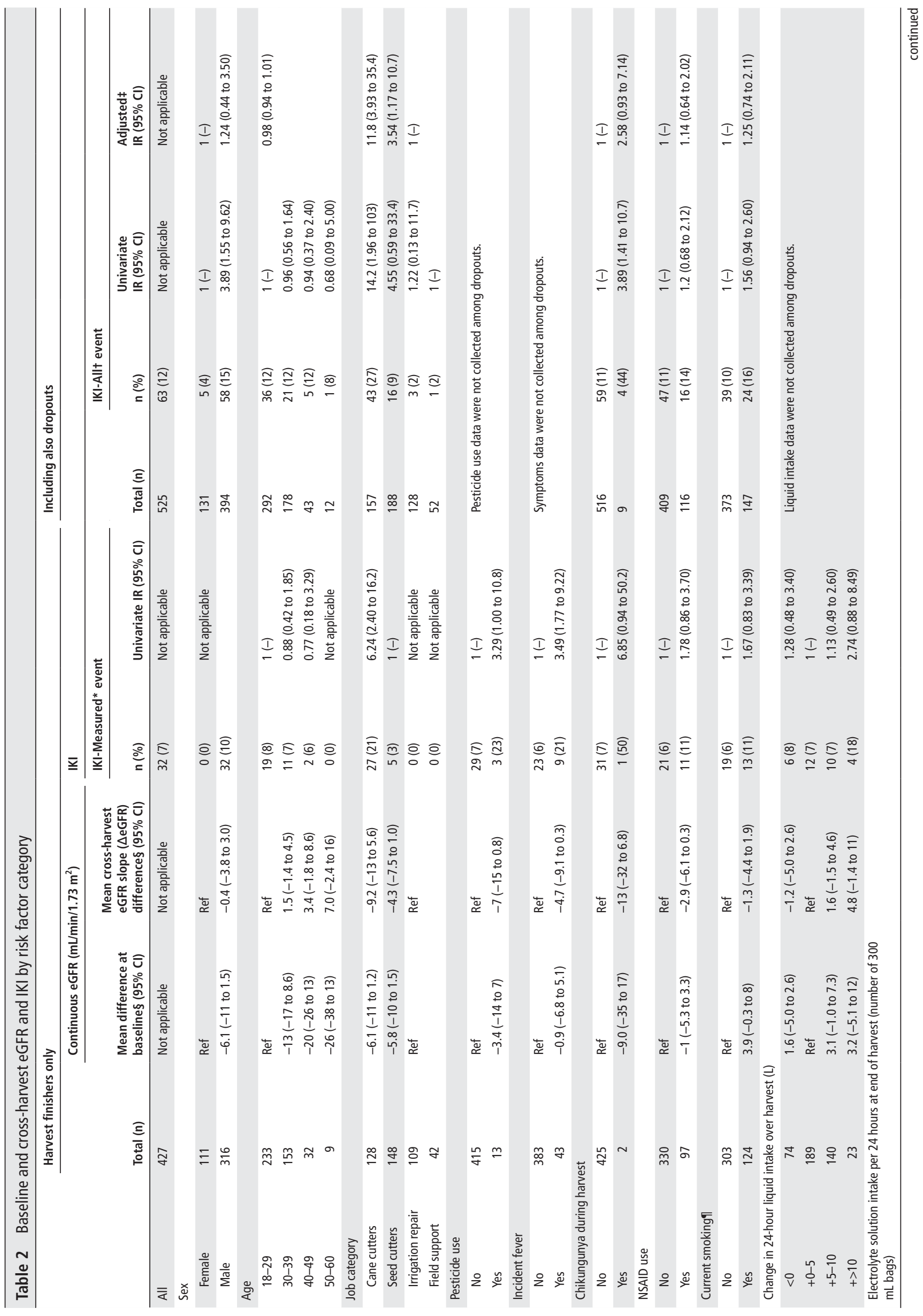




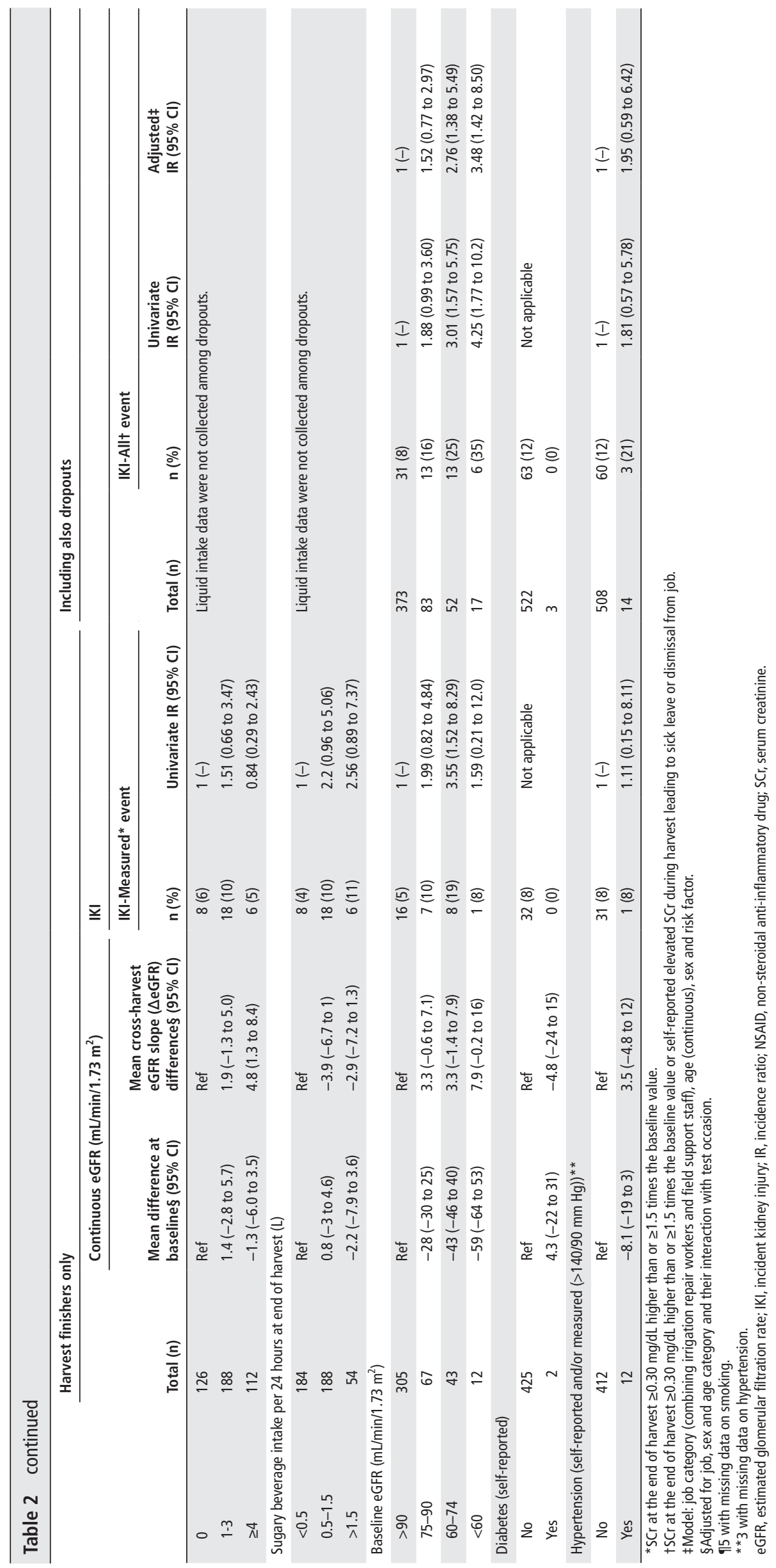




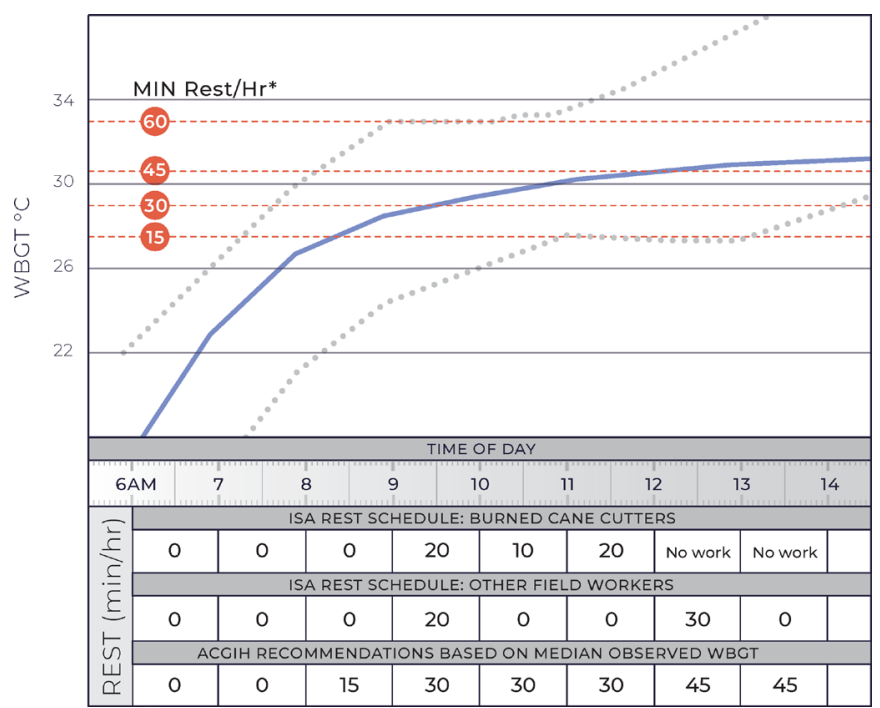

Figure 1 Median (solid blue line) and 90\% range (grey dotted lines) wet-bulb globe temperature (WBGT) in the sugarcane fields of Ingenio San Antonio (ISA) during harvest in 2017-2018. The ISA rest schedules during harvest in 2017-2018 are compared with the American Conference of Governmental Industrial Hygienists (ACGIH) recommendations for heavy physical work according to the median WBGT. *Threshold limit values (red dashed lines) for the number of minutes of rest per hour recommended by the $\mathrm{ACGIH}^{25}$ for heavy physical work.

sex was calculated restricted to seed cutters as there were no female burned cane cutters (table 1) and very few events in other work groups (table 2).

eGFR was modelled with mixed-effects linear regression using an unstructured covariance matrix for the random intercept and slope for each worker, estimated using the mixed command. Age group, sex and job were included as fixed effects in all models and other risk factors were entered separately. Interactions between test occasion and risk factors were assessed to model mean eGFR trends ( $\triangle$ eGFR) with 95\% CI across harvest.

To further explore self-reported fever, we assessed median baseline and cross-harvest change in $\mathrm{C}$ reactive protein (CRP) between IKI and job groups. All statistical analyses were conducted using Stata V.15.

\section{RESULTS}

\section{WBGT measurements}

WBGT measurements were plotted against the WBGT/rest limits at which the American Conference of Governmental Industrial Hygienists (ACGIH) considers there to be a risk of heat illness during heavy physical activity. ${ }^{25}$ This revealed a gap between practice and guidelines (figure 1).

\section{Participation}

After preharvest testing, 545 fieldworkers in the teams selected for the study were employed (figure 2). Five workers lacked Lund University serum samples either from baseline or end-harvest and were excluded. Workers were predominantly men under 40 (67\%), with some variation by job (table 1$)$.

Between baseline and end-harvest, 113 (21\%) workers dropped out. Of these, 98 (87\%) were contacted. Only 15 (3\% of all enrolled in the study) were lost completely. Dropout was more common among those with low baseline eGFR (33\% among those with $<60 \mathrm{~mL} / \mathrm{min} / 1.73 \mathrm{~m}^{2}$ vs $20 \%$ among those with $\left.>90 \mathrm{~mL} / \mathrm{min} / 1.73 \mathrm{~m}^{2}\right)$ and higher age $(26 \%$ above 40 years vs $20 \%$ below), but relatively constant between jobs (range $17 \%-23 \%)$.

\section{Kidney injury incidence and cross-harvest eGFR trends}

Of the 427 workers examined at baseline and end-harvest, 32 (7\%) had IKI (table 2). Among the 98 located dropouts, 31 (32\%) self-reported creatinine elevation. Of those, 19 indicated leaving before end-harvest due to high SCr and the other 12 had been on sick leave due to creatinine elevation. Among these 12, 3 did not return to work because work was too hard or for personal reasons and 9 were not present or notified the day of testing. In total, $63(12 \%)$ of the 525 participating fieldworkers had IKI-All during harvest.

Overall eGFR decreased by 4.6 (95\% CI 3.2 to 6.0 ) $\mathrm{mL} /$ $\min / 1.73 \mathrm{~m}^{2}$ during harvest.

\section{Kidney injury risk factors}

IKI varied significantly by job category. IKI-Measured only occurred in men among burned cane cutters (21\%) and seed cutters (3\%). For IKI-All, incidence increased to $27 \%$ among burned cane cutters and to $9 \%$ among seed cutters (including

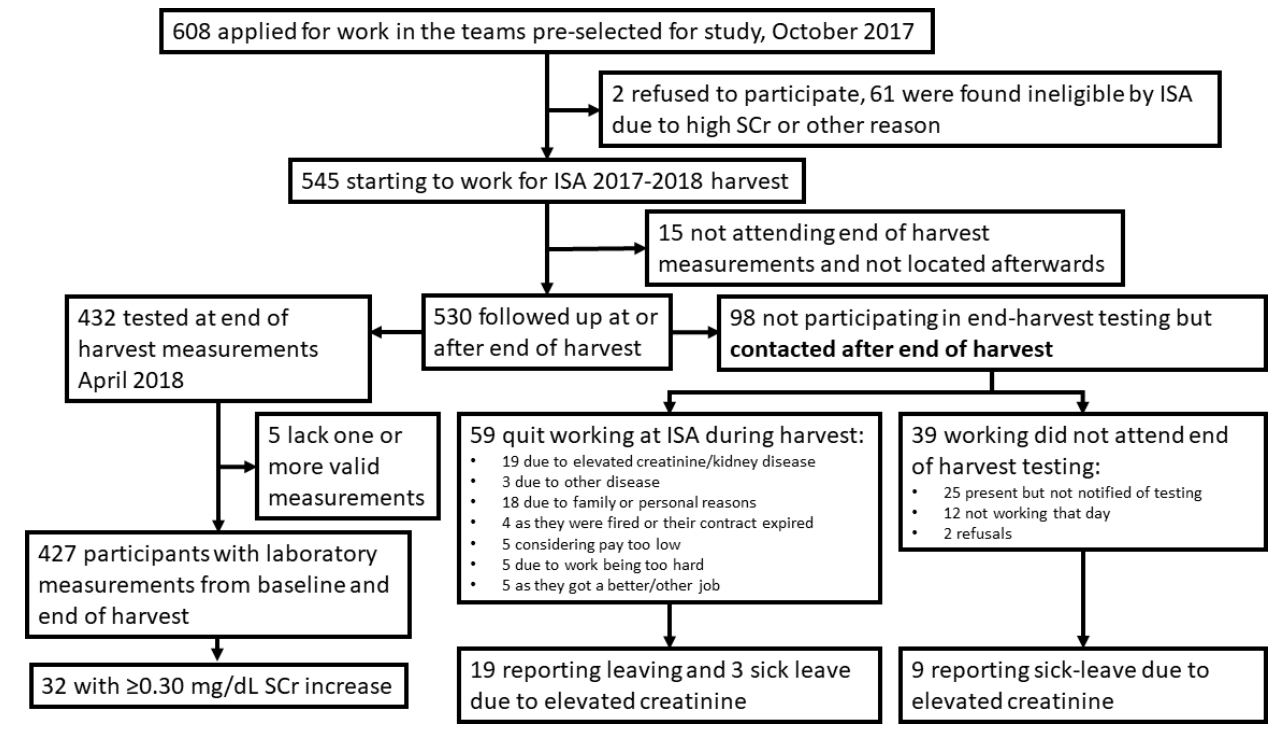

Figure 2 Participant flow chart. ISA, Ingenio San Antonio; SCr, serum creatinine. 


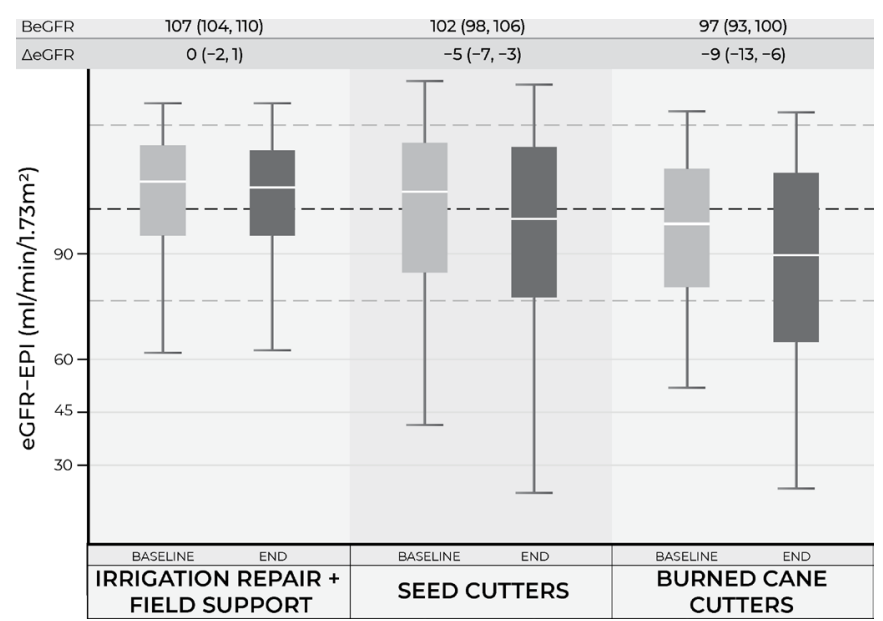

Figure 3 Renal function (eGFR) by job and time of testing. Dashed lines indicate median (black) and 90\% range (grey) eGFR in administrative staff at baseline. BeGFR denotes mean (95\% CI) baseline eGFR. $\triangle$ eGFR denotes mean $(95 \% \mathrm{CI})$ cross-harvest change in eGFR. Includes only workers measured before and at the end of harvest. eGFR, estimated glomerular filtration rate. EPI denotes eGFR is estimted according to the Chronic Kidney Disease Epidemiology Collaboration equation.

five women) (table 2). After age and sex adjustment, IKI-All incidence remained significantly elevated among cane and seed cutters compared with irrigation repair workers and field support staff. Adjusting for baseline eGFR reduced the age-adjusted and sex-adjusted IKI-All IR to 9.3 (95\% CI 3.2 to 28.3) for burned cane cutters and 3.3 (95\% CI 1.1 to 9.9) for seed cutters.

Cross-harvest eGFR declines varied by job (figure 3), with age-adjusted and sex-adjusted $\Delta$ eGFR -9.2 (95\% CI -12.9 to 5.6) among burned cane cutters and -4.3 (95\% CI -7.5 to -1.0) $\mathrm{mL} / \mathrm{min} / 1.73 \mathrm{~m}^{2}$ among seed cutters, with field support staff and irrigation repair workers as referent (table 2). The difference between burned cane and seed cutter was statistically significant $(p=0.01)$. These results did not change markedly after adjustment for baseline eGFR.

IKI-All incidence sex differences were non-significant among seed cutters (male/female IR $0.87,95 \%$ CI 0.30 to 2.51 ), and there were no sex differences in age- and job-adjusted $\Delta \mathrm{eGFR}$. Age was inversely associated with $\triangle \mathrm{eGFR}$ and IKI, which was strengthened when adjusting for baseline eGFR category, with a 1 -year age increase associated with a 0.96 (95\% CI 0.92 to 0.99 ) IR decrease.

IKI-All increased with decreased baseline renal function, while $\triangle \mathrm{eGFR}$ was worse among those with higher baseline renal function. Cross-harvest change in liquid intake was not clearly associated with IKI nor $\triangle \mathrm{eGFR}$, neither was absolute liquid intake. There was a tendency towards more IKI with increased sugary drink intake. High boli intake was associated with less $\Delta \mathrm{eGFR}$ decline, but not associated with IKI. Self-reported pesticide use, although infrequent $(n=13$, from various job categories), was borderline significantly associated with IKI-Measured in univariate analysis and $\triangle \mathrm{eGFR}$. End-harvest incident fever was associated with IKI-Measured, as was the inflammatory marker CRP, which increased eightfold in IKI workers during harvest while remaining stable in others. Workers self-reporting fever had significantly elevated CRP levels (online supplementary 2).

\section{DISCUSSION}

IKI among sugarcane fieldworkers during harvest was frequent (12\% IKI-All), with events concentrated among burned cane cutters (27\%; table 2). The IKI term was chosen as an epidemiological measure of substantial change in renal function over a specific time frame longer than that specified for AKI. ${ }^{24}$ Similar studies have found high cross-harvest kidney injury incidence, especially among burned cane cutters, $14 \%{ }^{11}$ and $19 \%,{ }^{14}$ with the first study following cutters after only 9 weeks and the latter not reporting on loss to follow-up.

Our results reflect a substantial healthy worker selection effect. Most dropouts were tracked, and the rate of self-reported IKI (elevated SCr) among the dropouts was four times higher than among those measured at end-harvest (32\% vs $7.5 \%$ ). Neglecting dropouts introduces selection bias and impedes future evaluation of intervention effects: improved outcomes among non-dropouts could be attributed to intervention effects but may also arise if the mill improves detection of ill workers and/or applies stricter criteria for return to work.

We assessed the validity of the use of IKI including self-reported IKI. Twenty-six out of 32 workers with measured and 23 out of 31 with self-reported IKI in year 1 returned for pre-employment testing at year 2, as did 372 workers without IKI. In a mixed-effects linear regression model adjusting for age, sex and job, the baseline-to-baseline eGFR decline was 9.6 (95\% CI 14.3 to 4.8 ) and $5.3(10.2$ to 0.5$) \mathrm{mL} / \mathrm{min} / 1.73 \mathrm{~m}^{2}$ larger in the measured and self-reported IKI groups, respectively, than in non-IKI workers. Worse kidney function at year 2 baseline 12 months later strengthens IKI-Measured as a valuable intermediate endpoint ${ }^{14}$ and indicates the validity of self-reported IKI, respectively. Further, reliable self-report of elevated SCr is not surprising as the importance of this biomarker is well understood in the community of workers, especially as it determines eligibility for hiring and for maintaining employment.

A nearby community cohort reported a small seasonal kidney function decline. ${ }^{26}$ The marked differences between workers in different jobs with similar outdoor heat exposure at work during the harvest indicate that seasonal effects alone cannot explain our findings. ${ }^{27}$

Cross-harvest eGFR declines were smaller and IKI events rare among workers judged to have low-moderate physical demands, but who share the very hot climatic conditions with their colleagues working more intensely. This suggests that an important driver of kidney injury in this setting is heavy physically demanding work. As in all observational research, unmeasured risk factors cannot be ruled out, but such factors must then be highly prevalent in cutters, but not in field support staff working just a few metres away.

Very few workers reported pesticide use during harvest. Considering that their jobs at the mill do not imply direct pesticide exposure and the low proportion reporting pesticide use, it is unlikely that a large proportion of IKI events could be attributed to pesticide exposure during harvest, a finding in line with previous studies. ${ }^{491213}$ To better understand a possible role of pesticides, exposure during non-harvest must be thoroughly assessed in all workers. Also, detailed information on pesticide use from the mill and investigations in workers with potentially higher exposure (weeders) are needed and planned for years 2 and 3 , as these could overcome potential validity problems of self-reported pesticide use. Most other explanatory variables are also self-reported, which is a limitation of this study.

Reduced baseline kidney function was a risk factor for IKI-All but not for $\triangle \mathrm{eGFR}$ decline. This is probably explained by three mechanisms: (1) a few individuals had extreme changes $(\Delta \mathrm{eGFR}$ restitution by $>20$ or loss by $>50 \mathrm{~mL} / \mathrm{min} / 1.73 \mathrm{~m}^{2}$ ) on the two ends of baseline eGFR distribution; (2) the relationship between SCr and eGFR is non-linear (a $0.3 \mathrm{mg} / \mathrm{dL}$ SCr increase at low 
eGFR implies much smaller eGFR decrease than at high eGFR); and (3) workers with low initial eGFR were more likely to drop out with IKI.

Evidence suggested inflammation may be associated with kidney injury, as others have reported. ${ }^{7812232628}$ To our knowledge, no study has identified the cause of inflammation or made a clear distinction between inflammation from heat injury ${ }^{29}$ versus infection. Reverse causation is unlikely as end-harvest CRP levels among IKI workers (online supplementary 2) were higher than normally seen in dialysis patients ${ }^{30}$ and middle-income country predialysis patients, ${ }^{31}{ }^{32}$ despite those patients having lower eGFR.

Reverse causation, residual confounding and measurement error limit interpretation concerning the role of hydration. While low liquid intake may predispose to kidney injury, high intake may indicate kidney injury causing poor urine concentration ability or strenuous work, ${ }^{3}$ potentially explaining why some studies ${ }^{43}$ identify high liquid intake as a risk factor and we find no association. Acute kidney damage has been reported in well-hydrated workers. ${ }^{7}$ Likewise, exertional heat stroke, a condition also characterised by systemic inflammation and organ damage, ${ }^{29}$ may also occur in well-hydrated individuals. ${ }^{34}$ A more complex interaction between water intake, physical labour and heat exposure is likely, with avoidance of dehydration not necessarily incurring complete protection against effects of heat on the kidney.

Nonetheless, hydration status should be assessed during repeated work shifts to adequately understand the role of dehydration in $\mathrm{CKDu}$ pathogenesis, but such measurements are complex in a field setting. ${ }^{35}$ Electrolyte solution intake has been associated with less kidney injury, ${ }^{4612} 13$ and our results agree partially: less cross-harvest eGFR decline, but no clear protective effect against IKI among those drinking the most bolis. A potential harmful effect of sugary beverages should be further considered. ${ }^{36}$ Drinking water contamination is unlikely considering that no nephrotoxic substances have been found in drinking water at the mill or within its vicinity, ${ }^{1737}$ nor in routine monitoring by the mill.

Muscular mass and diet could influence SCr levels and thus our results. Future studies should consider using glomerular filtration rate markers independent of this, for example, cystatin C.

The error introduced by incomplete mixing at the laboratory is a limitation, reduced by the correction using an internal standard. The correction procedure has been validated experimentally, and the assumed true sodium level of $140 \mathrm{mmol} / \mathrm{L}$ for the correction is in accordance with observations in sugarcane workers in the region. Associations observed are likely real, but we acknowledge there might be associations not observed due to the increased non-differential noise introduced by the error and the introduction of a correction factor.

Our assessment of workload for year 1 was observation-based, but preliminary analysis of HR measurements from year 2 confirms workload ordering (based on $\% \mathrm{HR}_{\mathrm{Max}}$ ): burned cane cutters had the highest proportion of the work shift at high levels of $\% \mathrm{HR}_{\mathrm{Max}}$, followed by seed cutters and irrigation repair workers, and with field support staff not yet measured.

Efforts are in process in years 2 and 3 to track the impact of interventions improvements, as current preventive measures seem inadequate for cutters. Improvements include adoption of rest schedules closer to the ACGIH guidelines, breaks earlier in the workday, and guaranteeing accessibility to water, tents for all job groups and increased adherence to the prescribed interventions. The current study of existing practices will be used as a historical control to evaluate the effectiveness of these measures.

\section{CONCLUSION}

Our results provide evidence for an association between physically demanding job tasks and kidney injury in a population exposed to high environmental heat levels. Workers considered to have the highest workload had more cross-harvest kidney damage than workers with less workload. Work practices preventing heat stress should be strengthened in design and implementation and their role in preventing kidney damage examined further. Research is needed to measure core body temperature, and the impact of an enhanced rest schedule and better access to water, and to investigate the role of inflammation. Future occupational studies should include longitudinal designs and account for a healthy worker effect by pursuing those lost to follow-up.

\section{Author affiliations}

${ }^{1}$ La Isla Network, Washington, District of Columbia, USA

${ }^{2}$ School of Public Health, University of Gothenburg Sahlgrenska Academy, Gothenburg, Sweden

${ }^{3}$ Faculty of Epidemiology and Population Health, London School of Hygiene and Tropical Medicine, London, UK

${ }^{4}$ Department of Laboratory Medicine, Division of Clinical Chemistry and

Pharmacology, Lund University Faculty of Medicine, Lund, Sweden

${ }^{5}$ Institute of Environmental Medicine, Unit of Occupational Medicine, Karolinska Institute, Stockholm, Sweden

${ }^{6}$ Facultad de Quimica y Farmacia, Universidad de El Salvador, San Salvador, El Salvador

${ }^{7}$ Programa SALTRA/ES, San Salvador, El Salvador

${ }^{8}$ School of Sport, Exercise and Rehabilitation Sciences, University of Birmingham, Birmingham, UK

${ }^{9}$ Occupational and Environmental Medicine, Sahlgrenska University Hospital, Gothenburg, Sweden

${ }^{10}$ University of Massachusetts Lowell, Lowell, Massachusetts, USA

Acknowledgements Shuchi Anand and Maria Emilia de Oliveira Montez Rath provided valuable comments on an earlier version of the manuscript. We also wish to thank Scarlette Poveda and Fatima Cerda for local coordination, data entering and management, William Martinez for locating and interviewing dropouts, and all other staff involved in data collection, as well as Ernesto Ariza for help in designing the graphs. We would also like to thank Adeera Levin for her continued support of intervention efforts via the International Society of Nephrology and all those that understand the value of mitigating identified risks while aetiology is being determined. Finally, we want to thank the sugarcane workers participating in this research.

Contributors CW, DHW and JG conceived and CW prepared the first protocol draft. The final protocol was produced with essential input from IW and KJ. SP, IW and CW collected the field data. DHW was the principal investigator and supervised the project. CW and EH were responsible for data management and statistical analyses. UE and JA were responsible for laboratory analyses. EH was responsible for drafting the manuscript, with input from all authors. All authors contributed to the revised drafts with text and/or intellectual content. All authors of this article have read and approved the final version submitted.

Funding This research was funded via the Adelante Initiative, a multistakeholder programme working to improve labour conditions in the sugarcane industry and beyond. Funding was provided by the German Investment Corporation (DEG) and the Ingenio San Antonio (ISA) sugar mill via the DEG's technical support programme for loan recipients. Under the technical support programme, the DEG funds half of the programme and the loan recipient, ISA in this case, the other. Laboratory analyses were paid directly to Lund University by ISA from the matching funds designated to the technical support programme. The remaining funds from ISA were dedicated to the logistical operations required by the mill to run its field interventions. DEG and Stavros Niarchos Foundation provided funds directly to the non-governmental organisation, La Isla Network, to pay for the management and execution of the research. Gothenburg and Lund Universities also supported the work by inkind funding.

\section{Competing interests None declared.}

\section{Patient consent for publication Not required.}

Ethics approval This study was approved by the Comité de Ética para Investigaciones Biomédicas (CEIB), Facultad de Ciencias Médicas, Universidad Nacional Autónoma de Nicaragua (UNAN - León (FWA00004523/IRB00003342). The biochemical investigation carried out at the Division of Clinical Chemistry and Pharmacology at Lund University in Sweden was approved by the Regional Ethical Review Board in Lund (reg no 2018-256). 
Provenance and peer review Not commissioned; externally peer reviewed. Data availability statement No data are available.

Open access This is an open access article distributed in accordance with the Creative Commons Attribution Non Commercial (CC BY-NC 4.0) license, which permits others to distribute, remix, adapt, build upon this work non-commercially, and license their derivative works on different terms, provided the original work is properly cited, appropriate credit is given, any changes made indicated, and the use is non-commercial. See: http://creativecommons.org/licenses/by-nc/4.0/.

\section{ORCID iD}

Erik Hansson http://orcid.org/0000-0002-9779-6820

\section{REFERENCES}

1 Wesseling C, Crowe J, Hogstedt C, et al. The epidemic of chronic kidney disease of unknown etiology in Mesoamerica: a call for interdisciplinary research and action. Am J Public Health 2013;103:1927-30.

2 Ramirez-Rubio 0, McClean MD, Amador JJ, et al. An epidemic of chronic kidney disease in central America: an overview. J Epidemiol Community Health 2013;67:1-3.

3 González-Quiroz M, Pearce N, Caplin B, et al. What do epidemiological studies tell us about chronic kidney disease of undetermined cause in Meso-America? A systematic review and meta-analysis. Clin Kidney J 2018;11:496-506.

4 Wesseling C, Aragón A, González M, et al. Heat stress, hydration and uric acid: a cross-sectional study in workers of three occupations in a hotspot of Mesoamerican nephropathy in Nicaragua. BMJ Open 2016;6:e011034.

5 Peraza S, Wesseling C, Aragon A, et al. Decreased kidney function among agricultural workers in El Salvador. Am J Kidney Dis 2012;59:531-40.

6 Butler-Dawson J, Krisher L, Yoder H, et al. Evaluation of heat stress and cumulative incidence of acute kidney injury in sugarcane workers in Guatemala. Int Arch Occup Environ Health 2019:73.

7 Sorensen CJ, Butler-Dawson J, Dally M, et al. Risk factors and mechanisms underlying Cross-shift decline in kidney function in Guatemalan sugarcane workers. J Occup Environ Med 2019;61:239-50.

8 Paula Santos U, Zanetta DMT, Terra-Filho M, et al. Burnt sugarcane harvesting is associated with acute renal dysfunction. Kidney Int 2015;87:792-9.

9 García-Trabanino R, Jarquín E, Wesseling C, et al. Heat stress, dehydration, and kidney function in sugarcane cutters in El Salvador--A cross-shift study of workers at risk of Mesoamerican nephropathy. Environ Res 2015:142:746-55.

10 Wegman DH, Apelqvist J, Bottai M, et al. Intervention to diminish dehydration and kidney damage among sugarcane workers. Scand I Work Environ Health 2018:44:16-24.

11 Wesseling C, Aragón A, González M, et al. Kidney function in sugarcane cutters in Nicaragua--A longitudinal study of workers at risk of Mesoamerican nephropathy. Environ Res 2016;147:125-32.

12 Laws RL, Brooks DR, Amador JJ, et al. Biomarkers of Kidney Injury Among Nicaraguan Sugarcane Workers. Am J Kidney Dis 2016;67:209-17.

13 Laws RL, Brooks DR, Amador JJ, et al. Changes in kidney function among Nicaraguan sugarcane workers. Int J Occup Environ Health 2015;21:241-50.

14 Kupferman J, Ramírez-Rubio 0, Amador JJ, et al. Acute kidney injury in sugarcane workers at risk for Mesoamerican nephropathy. Am J Kidney Dis 2018;72:475-82.

15 Lucas RAl, Bodin T, García-Trabanino R, et al. Heat stress and workload associated with sugarcane cutting - an excessively strenuous occupation! Extrem Physiol Med $2015 ; 4$
16 Bodin T, García-Trabanino R, Weiss I, et al. Intervention to reduce heat stress and improve efficiency among sugarcane workers in El Salvador: phase 1. Occup Environ Med 2016;73:409-16.

17 Ingenio San Antonio - Cronología de Actividades Médicas \& Ambientales, 2019. Available: http://isaresource.com/es/cronologia-de-actividades-medicas-yambientales/ [Accessed 08 Aug 2019].

18 Solís Zepeda GA. Impacto de las medidas preventivas para evitar El deterioro de la función renal POR El síndrome de GOLPE POR calor en trabajadores agrícolas del Ingenio San Antonio del Occidente de Nicaragua, ciclo agrícola 2004-2006. León: Universidad Nacional Autónoma de Nicaragua, 2007.

19 McClean MD, Laws RL, Ramirez Rubio O, Brooks D. Industrial Hygiene/Occupational health assessment: evaluating potential hazards associated with chemicals and work practices at the Ingenio San Antonio (Chichigalpa, Nicaragua) Boston University School of Public Health; 2010. http://www.cao-ombudsman.org/documents/ FINALIHReport-AUG302010-ENGLISH.pdf

20 Bonsucro, 2019. Available: https://www. bonsucro.com/

21 La Isla network, 2019. Available: https://laislanetwork.org/

22 Adelante initiative, a platform for change: La Isla network, 2017. Available: www. adelanteinitiative.org [Accessed 02 Feb 2019].

23 Fischer RSB, Mandayam S, Chavarria D, Palma L, Murray KO, et al. Clinical evidence of acute Mesoamerican nephropathy. Am J Trop Med Hyg 2017:97:1247-56.

24 Khwaja A. KDIGO clinical practice guidelines for acute kidney injury. Nephron Clin Pract 2012;120:c179-84.

25 OSHA. Osha technical manual (OTM), 2017. Available: https://www.osha.gov/dts/ osta/otm/otm_iii/otm_iii_4.html

26 Gonzalez-Quiroz M, Smpokou E-T, Silverwood RJ, et al. Decline in kidney function among apparently healthy young adults at risk of Mesoamerican nephropathy. J Am Soc Nephrol 2018:29:2200-12.

27 Pearce N, Caplin B. Let's take the heat out of the CKDu debate: more evidence is needed. Occup Environ Med 2019;76:357-9.

28 Fischer RSB, Vangala C, Mandayam S, et al. Clinical markers to predict progression from acute to chronic kidney disease in Mesoamerican nephropathy. Kidney Int 2018:94:1205-16.

29 Leon LR, Bouchama A. Heat stroke. Compr Physiol 2015;5:611-47.

30 Arici $\mathrm{M}$, Walls J. End-Stage renal disease, atherosclerosis, and cardiovascular mortality: is C-reactive protein the missing link? Kidney Int 2001;59:407-14.

31 Adejumo OA, Okaka El, Okwuonu CG, et al. Serum C-reactive protein levels in pre-dialysis chronic kidney disease patients in southern Nigeria. Ghana Med J 2016:50:31-8.

32 Razeghi E, Parkhideh S, Ahmadi F, et al. Serum CRP levels in pre-dialysis patients. Ren Fail 2008;30:193-8.

33 Sanoff SL, Callejas L, Alonso CD, et al. Positive association of renal insufficiency with agriculture employment and unregulated alcohol consumption in Nicaragua. Ren Fail 2010;32:766-77.

34 Cotter JD, Thornton SN, Lee JKW, et al. Are we being drowned in hydration advice? Thirsty for more? Extrem Physiol Med 2014;3.

35 Armstrong LE. Assessing hydration status: the elusive gold standard. J Am Coll Nutr 2007:26:575S-84.

36 Sánchez-Lozada LG, Roncal-Jimenez CA, García-Arroyo FE, et al. The perils of rehydrating with soft drinks following heat and exercise. Am J Physiol Regul Integr Comp Physiol 2019;316:R187-R188.

37 Atkins D, McClean M, Brooks D. Phase I environmental monitoring: April 2010 assessment of water samples. Boston University School of Public Health; 2010. http:// www.cao-ombudsman.org/cases/document-links/documents/Water_sampling_ report_August2010.pdf 